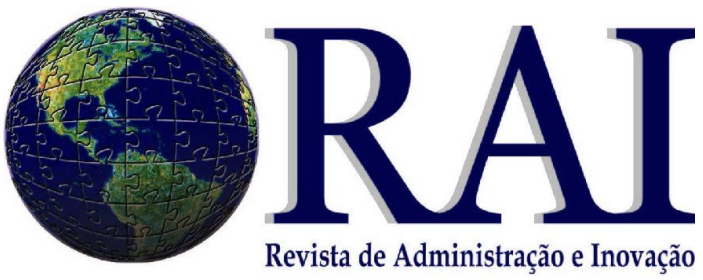

\title{
DEMANDAS DE INTEGRAÇÃO DE TECNOLOGIA DA INFORMAÇÃO EM EMPRESA DO SETOR DE AUTOPEÇAS. UM ESTUDO DE CASO
}

\author{
Milton de Abreu Campanario \\ Coordenador do Programa de Pós-Graduação em Administração - Uninove \\ Doutor em Economia - Cornell University \\ E-mail: campanario@ uninove.br [Brasil] \\ Carlos Alberto Santa Maria Garcia \\ Mestre em Administração - Uninove \\ E-mail: albertomg@uol.com.br [Brasil]
}

\section{RESUMO}

Neste trabalho pretendemos mostrar as demandas de integração de tecnologia da informação em empresa do setor de autopeças. O planejamento realizado para atendê-las considera os aspectos de redes de comunicações, equipamentos, sistemas operacionais e aplicativos e impactos na organização. A globalização dos mercados provocou mudanças na atuação da indústria automobilística mundial e brasileira. $\mathrm{O}$ segmento brasileiro de autopeças também foi atingido, precisando agir e adaptar-se rapidamente para um novo tipo de relacionamento com seus principais clientes, as montadoras. A empresa onde este estudo de caso acontece está inserida neste contexto. Associado a esse processo, ela também tem que atender a estratégia de unificação em rede do processamento de informações do grupo como um todo.

Palavras-chave: Globalização; Indústria automotiva; Indústria de autopeças; Tecnologia da informação. 
Demandas de integração de tecnologia da informação em empresa do setor de autopeças. um

\section{INTRODUÇÃO}

estudo de caso

A globalização é a palavra de ordem no mundo atual, no qual a indústria automobilística e a de autopeças, em fase de profunda transformação, se inserem e se integram.

As fusões entre as grandes montadoras, as definições que englobam as novas fábricas de veículos do Mercosul, os investimentos estrangeiros, os novos sistemas de produção e a globalização acarretam, conseqüentemente, uma reestruturação nos diferentes segmentos envolvidos nesse mercado. No caso da indústria automobilística brasileira, além da competitividade estar ainda mais acirrada com a entrada dos novos fornecedores globais, o mercado necessita de alternativas para absorver toda a capacidade de produção nacional.

Conscientes de que têm que enfrentar grandes desafios para manterem-se atuantes nesse mercado de competitividade global, empresas traçam suas estratégias de atuação, que visam integração em âmbito mundial, apoiando-se fortemente na tecnologia da informação, cuja infra-estrutura de comunicações desempenha papel fundamental.

A estratégia deve considerar que rapidez, flexibilidade e qualidade, tanto no produto quanto na prestação de serviços, são critérios essenciais de concorrência, principalmente para um grupo com atividades mundiais. Nesse aspecto, a uniformidade empresarial dos sistemas de informações e comunicações, como o planejamento e a liderança desempenham papel decisório, sendo essa a melhor condição para continuar modelando a posição de participante no mercado mundial.

É importante, também, ressaltar que isso faz com que os custos de processamento de informações sejam minimizados mundialmente. Assim, as vantagens de desenvolvimentos contínuos em tecnologia da informação transformam todas as empresas de um grupo em uma rede global de comunicações. Ampliando o uso do processamento de informações, compartilha-se o know-how de aplicações em âmbito mundial.

E, levando-se em conta os processamentos das informações, é necessário um trabalho conjunto de todos funcionários, pois as tarefas para isso são complexas e exigem que cada pessoa, quer seja nas unidades descentralizadas ou nas áreas centrais de processamento de informações, atue com muito empenho vontade e coloque toda sua experiência nos projetos existentes.

\section{GLOBALIZAÇÃO E REVOLUÇÃO TECNOLÓGICA}

A visão que se tem da economia internacional, neste fim de século, é a de que as mudanças ocorrem em ritmo acelerado, levando os países a se adaptarem a esse fenômeno chamado "globalização".

Globalização é o conjunto de transformações na ordem política e econômica mundial que vem acontecendo nas últimas décadas. $\mathrm{O}$ ponto central da mudança é a integração dos mercados numa aldeia-global, explorada pelas grandes corporações internacionais. Os estados abandonam gradativamente as barreiras tarifárias para proteger sua produção da concorrência dos produtos estrangeiros e abrem-se ao comércio e ao capital internacional. Na economia que se globaliza a fonte principal de impulso dinâmico decorre da capacidade de inserção internacional.

Ainda sobre a globalização, segundo Tapscott (1997), é ela que está impulsionando a extensão da tecnologia. O novo mundo geopolítico está abrindo novos mercados em todos os

RAI - Revista de Administração e Inovação, São Paulo, v. 1, n. 2, p. 42-54, 2004. 
lugares, exigindo uma resposta global. Empresas globais precisam ser capazes de conectar-se com seus clientes, fornecedores, empregados e parceiros em todos os cantos do mundo. Novas oportunidades nos mercados financeiros globais requerem uma infra-estrutura de informação para exploração. Tudo isso está contribuindo, internacionalmente, para reformulações da estrutura organizacional e de indústrias inteiras.

O grande desafio das economias industrializadas é encontrar a forma adequada de instalar-se no processo de globalização, aumentando a sua capacidade de auto-organizar-se e dar solução a seus problemas. Esse processo tem sido acompanhado de uma intensa revolução nas Tecnologias da Informação - comunicações, computadores, telefonia e televisão.

Importante também, nesse processo, são as mudanças significativas no modo de produção das mercadorias. Auxiliadas pelas facilidades na comunicação e nos transportes, grandes empresas instalam suas fábricas em qualquer lugar do mundo onde existam as melhores vantagens fiscais, mão-de-obra e matérias-primas baratas.

A rápida evolução e a popularização da Tecnologia da Informação têm sido fundamentais para agilizar o comércio e as transações financeiras entre países. Tudo isso permite uma integração mundial sem precedentes.

\section{INDÚSTRIA AUTOMOBILÍSTICA}

\section{1 ÂMBITO MUNDIAL}

A indústria automobilística mundial vive esse processo de globalização intensamente. As recentes crises econômicas e a conseqüiente reorganização nos padrões de concorrência, vêm impondo às grandes empresas uma urgente necessidade de reestruturação organizacional. Nesse sentido, muitas empresas estão fundamentando seu comportamento competitivo no paradigma da indústria japonesa e de seus métodos de gestão de produção, que podem ser resumidos, em linhas gerais, na idéia da "produção enxuta" e nas filosofias de qualidade total e de produção just-in-time. Em particular, tais empresas passaram a adotar uma estratégia voltada a uma maior descentralização produtiva e, para isso, passaram a se concentrar em seu negócio central (core business), e paralelamente, desenvolver/subcontratar uma série de outras empresas (terceiros), especializadas em atividades/serviços de apoio, ou fornecedoras de peças/componentes/sub-conjuntos dos produtos finais, conforme Amato Neto (1996).

A idéia de produção enxuta contrapõe-se ao desperdício. Segundo Womack e Jones (1998), o pensamento enxuto é uma forma de especificar valor, alinhar na melhor sequiência as ações que criam valor, realizar essas atividades sem interrupção toda vez que alguém as solicita e realizá-las de forma cada vez mais eficaz. Em suma, o pensamento enxuto é uma forma de fazer cada vez mais com cada vez menos - menos esforço humano, equipamento, tempo e espaço - e, ao mesmo tempo, aproximar-se cada vez mais dos clientes oferecendo exatamente o que eles desejam É também é uma maneira de tornar o trabalho mais satisfatório, oferecendo feedback imediato sobre os esforços para transformar o desperdício em valor.

Essa nova perspectiva de lidar com o processo produtivo provocou profundas mudanças na tradicional estrutura organizacional voltada para a produção em massa. Tais mudanças podem ser compreendidas, principalmente, segundo Amato Neto (1996), através de

RAI - Revista de Administração e Inovação, São Paulo, v. 1, n. 2, p. 42-54, 2004. 
Demandas de integração de tecnologia da informação em empresa do setor de autopeças. um estudo de caso

três elementos básicos, que compreendem as novas formas de organização do trabalho; a revolução na base técnica com o advento das novas tecnologias de base micro-eletrônica e, finalmente, o novo padrão de inter-relacionamento entre firmas e/ou empresas.

A respeito desse relacionamento afirma-se, em outro trecho do trabalho de Hoffman e Kaplinsky (1988), que desde os primórdios do antigo padrão de produção industrial, as grandes empresas do setor automobilístico provocaram o surgimento de um sem-número de pequenas empresas, fornecedoras de autopeças, que passaram a produzir vários tipos de produtos e componentes para as grandes montadoras da época (primeira metade deste século). Ainda que empresas como a Ford e a GM apresentassem elevados níveis de integração vertical, enquanto que a Chrysler e as empresas européias tendessem a comprar a maior parte dos componentes de firmas independentes, o fato é que a subcontratação já se fazia presente desde o nascimento da indústria automobilística. Porém, ainda que um grande número de peças e de componentes fossem adquiridas de filiais cativas, tais empresas desenvolviam seus projetos de produtos de forma independente do desenvolvimento do produto final (automóvel) a que os primeiros se destinavam. Dessa forma, uma série de problemas surgia no interrelacionamento entre contratantes (montadoras) e fornecedoras de autopeças.

\subsubsection{Mercado Brasileiro}

A indústria automobilística brasileira nasceu sob um sistema protecionista e de reserva de mercado, a partir da década de 1950. Esse setor influencia fortemente a economia brasileira, tanto pelo fato de seu produto, o automóvel, constituir-se no símbolo da vida moderna quanto pela série de investimentos e geração de empregos dela derivados.

Unido às grandes montadoras estrangeiras, o complexo automobilístico brasileiro compôs-se de todos elementos que importam no transporte rodoviário, construção das autoestradas, pavimentação das vias públicas urbanas, entre outros; de um conjunto enorme de segmentos industriais que experimentaram significativa expansão, como os responsáveis pela oferta de todos os insumos necessários à fabricação do automóvel, como borracha, pneus, vidro, aço etc., e ainda, de todo um conjunto de pequenas e médias empresas de autopeças.

O processo de desenvolvimento da indústria automobilística, no Brasil, passou por várias fases, experimentando períodos de bons e maus resultados. Atualmente, essa indústria encontra-se em fase de retração. Tal situação é reflexo da sequiência de crises que ultimamente atinge alguns países e que, dentro do processo mundial de globalização, acaba afetando os demais. Apesar de se distinguir os períodos mais agudos, suas origem e natureza são evidentemente única: a fragilidade econômica e institucional de países despreparados para a abertura ao fluxo de capitais externos, num volume inédito na história, conforme em Contágio global (1999).

É preciso estar preparado para responder às necessidades de um mercado cada vez mais globalizado e competitivo. Preocupar-se pois, com a estratégia competitiva é fazer com que a empresa tenha condições de enfrentar sua concorrência e estar sempre ativa no mercado. Está cada vez mais claro que a integração fornecedores-empresa-consumidores é um dos componentes vitais dessa nova competitividade global.

Observa-se que na mudança das relações entre firmas, os novos atributos do formato organizacional das empresas competitivas contemporâneas modificam as suas fronteiras, alterando radicalmente normas que regulam sua relação com fornecedores e clientes. Decisões relativas ao que se pode produzir internamente pelas próprias empresas e a aquisição de insumos, como adquiri-los são, cada vez mais, tomados em parceria com os

RAI - Revista de Administração e Inovação, São Paulo, v. 1, n. 2, p. 42-54, 2004. 
fornecedores. A competitividade delas depende de sua proximidade com fornecedores, em termos de desenvolvimento conjunto de produtos, troca de informação por meios eletrônicos, fluxos de entrega que minimizam estoques, garantia assegurada de desempenho de insumos e estabilidade nos contratos, de acordo com Coutinho e Ferraz (1995).

Ser competitivo é ser capaz de superar a concorrência naqueles aspectos de desempenho que os nichos de mercado visados mais valorizam, conforme Corrêa, Gianese e Caon (1999).

A rota da mentalidade enxuta, no Brasil, pode ser exemplificada pela Toyota, pioneira neste tipo de produção no Japão, através da construção de sua fábrica no nosso país para montagem de automóveis, onde prioriza o sistema de distribuição com eficiência e qualidade, segundo Ferro (1998).

Outra situação é a batalha de conceitos e práticas na produção de caminhões entre a Mercedes-Benz e a Volkswagen. Nesse caso o foco é essencialmente a produção. A Mercedes-Benz representa o intenso esforço de reestruturação de uma empresa típica de produção em massa. Uma instalação produtiva, inaugurada nos anos 50, está sendo transformada em uma planta enxuta com a difusão de atividades de kaizen e a reorganização da produção. Kaizen, segundo Womack e Jones (1998), significa melhoria incremental contínua. Por outro lado, a recém-construída fábrica de caminhões da Volkswagen, no município de Resende, do Rio de Janeiro, marca a difusão de novas idéias e práticas enxutas em uma fábrica totalmente nova. Uma delas é o conceito de consórcio modular em que sete fornecedores são responsáveis por parcela do investimento, pelas atividades de montagem e pelos estoques, entre outras mudanças, de acordo com Ferro (1998) é pioneiro em todo o mundo.

\section{AUTOPEÇAS BRASILEIRAS}

Assim como todas atividades humanas, a economia mundial se aperfeiçoa e cria novos parâmetros para o comércio entre as nações. O Brasil, há alguns anos, partiu definitivamente para atuar dentro do processo de globalização. Caíram as barreiras que nos protegiam da concorrência externa. Não há mais espaço para mercados cativos e superprotegidos, o que é, inegavelmente, uma mudança inexorável.

Desde o início de 1990 até os dias atuais, porém, tem-se procurado formas de amenizar os efeitos de desigualdades macroeconômicas que prejudicam o país. O custo interno de aumentar a produtividade, algumas vezes superior ao de outros países, e o chamado "custo Brasil", impostos que encarecem os produtos em mais de 15\%, são bons exemplos das adversidades a serem enfrentadas. Segundo Coutinho e Ferraz (1995), após quase uma década e meia de estagnação, as empresas se adaptaram, cada uma à sua maneira, principalmente durante dois períodos (1980-83 e 1989-92) nos quais a depressão econômica foi mais intensa. No primeiro, as empresas se ajustaram fundamentalmente no plano financeiro-patrimonial, reduzindo significativamente seus níveis de endividamento. Para tanto, contrabalançaram a redução de produção e demanda com crescentes ganhos não-operacionais. O segundo reajuste, realizado num quadro de abertura comercial, tem sido caracterizado por reestruturações da produção propriamente dita: concentração nas linhas de produtos competitivos; redução das atividades industriais realizadas internamente na empresa; "terceirização" de diversas atividades; compactação dos processos produtivos com corte substancial do emprego; programas de qualidade etc.

RAI - Revista de Administração e Inovação, São Paulo, v. 1, n. 2, p. 42-54, 2004. 
Demandas de integração de tecnologia da informação em empresa do setor de autopeças. um

estudo de caso

A indústria automobilística brasileira é uma das alavancas da economia do país, e em volume de produção está entre as dez primeiras do mundo. Embora haja todo esse processo de globalização, são considerados grandes produtores de automóveis os países cujo setor de autopeças supra, tanto a demanda das montadoras locais quanto as regionais (blocos econômicos). Para tanto, os investimentos devem ser significativos, justificando a permanência e atuação das empresas de autopeças num determinado país.

Outro aspecto é a popularização do conceito de carro mundial, cuja principal característica é o de ser produzido com peças desenvolvidas e adquiridas em qualquer país e que resultam em objetos absolutamente iguais. Segundo Davis (1990), a companhia global parte do princípio de que o mundo é um todo e, portanto, seus habitantes procuram produzir e vender a mesma mercadoria em toda parte. As decisões estratégicas sobre cada função de negócios (pesquisa, projeto, engenharia, compra, fabricação, comercialização, venda, distribuição e serviço) são tomadas em bases mundiais. Todas as atividades são coordenadas entre os países, sendo que cada uma delas está concentrada no país mais vantajoso. O princípio é de que a tecnologia, conforme citado por Davis (1990, p. 176) "[...] impele o mundo para uma plebeidade convergente e, em conseqüência, há o surgimento de mercados globais para produtos de consumo padronizados [...]".

A indústria mundial de autopeças está enfrentando uma verdadeira revolução. $\mathrm{O}$ Brasil, obviamente, está inserido nesse contexto, cujos principais sintomas são as mudanças na relação entre montadoras e fornecedores. Cada vez mais as montadoras delegam a responsabilidade da produção. Trata-se da "desverticalização" ou transferência de grande parte da montagem dos veículos aos fabricantes de autopeças.

Com isso surge outro novo padrão de relacionamento cooperativo, o co-design, que é a engenharia básica do veículo desenvolvida por esses dois vértices da cadeia produtiva. Para não perder o espaço duramente conquistado, os fabricantes de autopeças têm canalizado grandes esforços na utilização de novas tecnologias. Um exemplo dessa situação é a planta da Volkswagen em Resende, que conta com uma maior participação e envolvimento dos fornecedores na produção dos veículos, através do fornecimento de conjuntos e subconjuntos montados previamente. Isso serve para aproximar ainda mais as montadoras com os fornecedores inclusive fisicamente através das respectivas plantas. $O$ fornecimento de subconjuntos facilita a montagem final, porque requer menor esforço de montagem, diminuindo assim os seus custos, além de reduzir os problemas de qualidade porque a maior parte dos subsistemas pode ser previamente testada. Há também benefícios em logística, com menor número de movimentações e de espaço alocado, de acordo com Ferro (1998). Outros aspectos importantes nesse processo são a qualidade absoluta e redução dos custos de produção.

\section{DEMANDAS E IMPACTOS DE INTEGRAÇÃO}

O modelo de tempo dos negócios no mundo industrial era definido a partir da perspectiva da empresa. A ênfase ficava nas reorientações e ações internas. Mesmo o esquema "das nove às cinco", que define um acontecimento que se repete com regularidade, vem mais da perspectiva industrial do produtor do que da percepção pós-industrial do consumidor. Quando a empresa se concentra no externo, ou melhor, no consumidor, ela transforma seu sentido de tempo. A meta passa ser a redução do intervalo de tempo decorrido entre a

RAI - Revista de Administração e Inovação, São Paulo, v. 1, n. 2, p. 42-54, 2004. 
necessidade identificada do cliente e a satisfação do mesmo, conforme Davis (1990). O planejamento de tecnologia da informação de uma empresa do setor de autopeças tem que atender as situações de transformação até aqui consideradas. Tais considerações representam as demandas e impactos de integração, para que a empresa possa continuar atuando nesse respectivo mercado, cujos principais demandas e impactos são:

\subsection{REDE DE COMUNICAÇÕES}

Essencial para a integração de uma empresa. A rede permite não só a comunicação com a matriz, mas com todas as empresas vinculadas. Uma das facilidades que a rede possibilita é o acesso a sistemas transacionais utilizados para atividades operacionais, permitindo uma atuação padronizada. As bases de dados podem ser acessadas por qualquer empresa do grupo. Pela padronização dos campos de arquivos, todos os usuários estarão acessando os bancos de dados principais, como também a unificação do número dos desenhos agilizará a busca de informações armazenadas.

Outro fator de muita importância é a troca de arquivos de desenhos, que permitirá às áreas de Engenharia aproveitarem qualquer desenho que já tenha sido desenvolvido por alguma empresa do grupo em qualquer parte do mundo. A agilidade, produtividade e segurança que esse sistema propicia, representa muito para a empresa no relacionamento de mercado junto a seus clientes.

Através de programas internos, também é possível trocar outros tipos de arquivo fazendo com que os usuários praticamente não sintam impacto algum em função da distância.

Voz e imagem também fazem parte desse contexto através da videoconferência.

A infra-estrutura dessa rede, utilizando tecnologia de ponta, formada por equipamentos de proteção chamados de firewall asseguram ao mesmo tempo, a integridade das informações e permitem que se tenha a segurança esperada por meio da criptografia.

O uso da internet é intenso, tanto pela utilização do correio eletrônico (e-mail) quanto para acesso a diferentes endereços (sites - homepages) que sejam do interesse da empresa. A rede mundial de comunicação também auxilia na divulgação institucional da empresa e no fornecimento de informações técnicas dos seus produtos. Pela intranet existe uma integração entre os diversos departamentos da empresa, facilitando a comunicação interna entre seus funcionários. Há também uma melhoria no intercâmbio entre clientes, fornecedores e distribuidores. Várias são as trocas de informações que uma empresa do setor de autopeças precisa ter com seus clientes, principalmente montadoras. São trocas de textos, planilhas e ultimamente, também desenhos. As facilidades de comunicação também chegam aos distribuidores que podem apresentar suas solicitações diretamente nos sistemas da empresa.

A rede de micros assume fundamental importância nesse contexto. Para a quase totalidade das vantagens da rede de comunicações, o microcomputador é imprescindível. Esses equipamentos precisam estar em rede, caso contrário não se tira o devido benefício dessa infra-estrutura. Tempo de resposta adequado, disponibilidade do acesso 24 horas por dia e compatibilidade dos equipamentos, também são aspectos considerados para a montagem dessa rede, que deverá estar sempre apta para suportar seu dimensionamento, novas formas de trabalho, que fazem com que diversos processos sejam alterados.

RAI - Revista de Administração e Inovação, São Paulo, v. 1, n. 2, p. 42-54, 2004. 
Demandas de integração de tecnologia da informação em empresa do setor de autopeças. um

\subsection{EQUIPAMENTOS}

estudo de caso

Todos os microcomputadores devem ter condições de acessar qualquer sistema da empresa. A configuração deve estar adequada para as necessidades existentes, não precisa ser necessariamente sempre o último lançamento.

Há também os notebooks que são ideais trabalhas em um escritório virtual, ou seja, vários colaboradores em diversos pontos. Através deles a empresa pode ser acessada de qualquer ponto do país ou do mundo, bastando, para tanto, apenas uma conexão telefônica para poder ligar esse equipamento e, via rede de comunicação, acessar a empresa. Isso permite discutir com os parceiros tendo, se necessário for, acesso às bases de dados.

No processamento de sistemas corporativos, a empresa precisa de servidores centrais. Isso atende as necessidades do volume de processamento diário de transações e integração com a matriz, características dos sistemas transacionais etc. Para gerenciamento da rede"multiplataforma", é recomendado um equipamento que traga velocidade de processamento, redundância e praticamente não apresente falha.

A integração do ambiente corporativo com as demais plataformas em rede apresenta complexidades, que se traduzem no uso de equipamentos como switches e roteadores, bem como o código de barras impresso nas embalagens dos produtos. Adoção de dessa medida faz com que novos sistemas sejam desenvolvidos e integrados ao ambiente hoje existente. $\mathrm{O}$ padrão e a compatibilidade dos equipamentos, somando-se ao processo de integração no grupo, se traduz em redução de custos e manutenção dos investimentos realizados.

\subsection{SOFTWARE}

Para atender a demanda de sistemas, integração e necessidades específicas da empresa, deve-se atentar para uma padronização de produtos.

No caso de sistemas operacionais isso traz impactos na cultura da organização, gera necessidade de treinamento, atualização de equipamentos etc. $\mathrm{O}$ uso de produtos como planilha eletrônica, processador de texto, banco de dados, gerenciador de projetos, linguagem de programação etc., reforçam a importância que todos sejam treinados constantemente.

O controle de documentos e formulários eletrônicos também deve integrar a estratégia da empresa. O ponto forte desse item é a base de dados que se forma, permitindo o arquivamento e recuperação de documentos. Isso influencia muito o modo de trabalho existente, especificamente no que diz respeito ao manuseio dos desenhos. Todos os usuários que precisam acessar o produto, poderão fazê-lo através do uso de estações de trabalho, que farão parte da rede de comunicações, e não mais de desenhos em papel.

Hoje as empresas ainda se utilizam, e muito, de desenhos em papel. Em algumas situações há problemas com relação à versão do desenho que alguém está utilizando. Com esse tipo de software, os problemas no chão de fábrica provenientes de uso indevido de versões, praticamente acabam, inclusive a necessidade de cópias e desenhos circulando pela empresa. Os benefícios são grandes, pois isso evita a produção de produtos com desenho errado. Outra vantagem é a transferência gradativa de todos os arquivos de desenhos em papel para o sistema.

Os chamados softwares CAD/CAM também devem ser contemplados, abrangendo produtos para aplicações em 2D e em 3D, nos casos em que se aplicam. O uso integrado com CIM também deve ser explorado.

RAI - Revista de Administração e Inovação, São Paulo, v. 1, n. 2, p. 42-54, 2004. 
O uso desses produtos resulta em diminuição de retrabalhos, melhor controle dos recursos, agilidade de processamento, expansão e melhoria da base de dados, tolerância a falhas etc. Permite também gerenciamento adequado do chamado custo total de propriedade, juntando-se ao software os equipamentos, serviços de manutenção e necessidades de treinamento.

\subsection{SISTEMAS}

Os diversos sistemas que estarão sendo desenvolvidos ou que sofrerão manutenção visam atender às necessidades dos usuários locais e à estratégia do grupo. Para tanto, devem se adequar às necessidades de mudança nos processos produtivos, novas formas de apresentação de resultados, unificação da base de dados, além de disponibilizar mais rapidamente informações para o processo de tomada de decisão.

Sistemas ERP (Enterprise Resources Planning) devem ser analisados e, dentro do possível, implementados, pois trazem facilidades de integração na cadeia de clientes e fornecedores. Esse direcionamento faz com que somente se trabalhe em projetos de curta duração que, tragam retorno, justifiquem os investimentos e estejam alinhados à estratégia da organização.

\subsection{ORGANIZAÇÃO}

Em decorrência do impacto de todas essas demandas de integração, a organização inteira sofre mudanças, principalmente a área de Tecnologia da Informação. Em muitos casos a necessidade de treinamento em novas ferramentas é evidente. Em outros, rotinas e processos executados ao longo de anos serão substituídos, assim como novas formas de trabalho serão implementadas. Tudo podendo ocorrer ao mesmo tempo, tendo que ser devidamente gerenciado e conduzido. O efeito dessa transformação no ambiente é grande e a resistência às mudanças precisa ser administrada com rigor para não se correr o risco de não atingir os objetivos.

A empresa está inserida num mercado extremamente disputado. Todo esse direcionamento em Tecnologia da Informação é para atender às demandas existentes nessa área, que possibilitem a empresa atuar em sua estratégia de vantagem competitiva.

A Figura 1 mostra os principais aspectos e os reflexos que o aumento de competitividade representa para a empresa na elaboração de seus produtos e o que isso gera em termos de necessidades de tecnologia da informação.

RAI - Revista de Administração e Inovação, São Paulo, v. 1, n. 2, p. 42-54, 2004. 
Demandas de integração de tecnologia da informação em empresa do setor de autopeças. um

estudo de caso

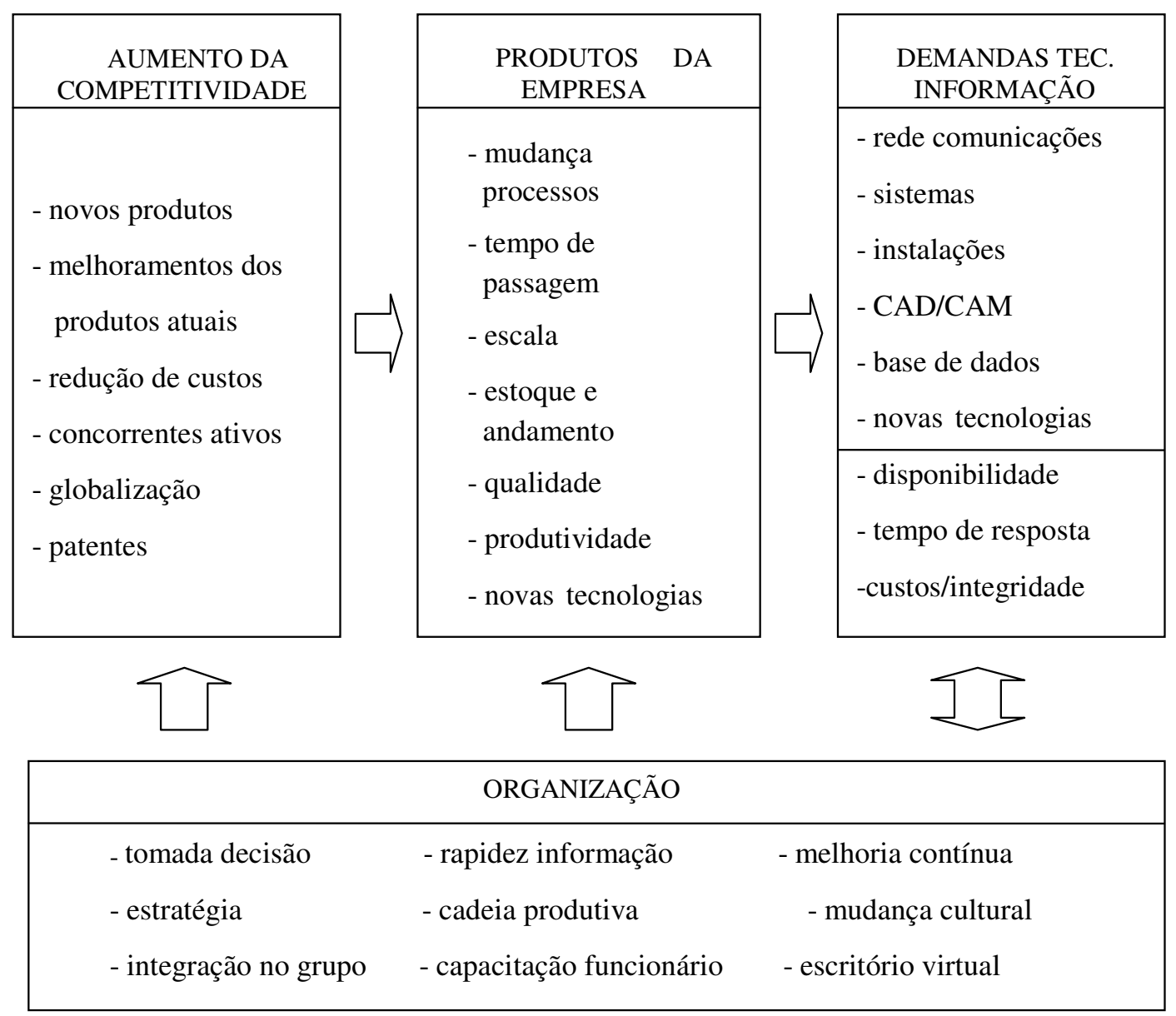

Figura 1: Demanda de integração. Aspectos principais.

Fonte: Os autores.

\section{CONSIDERAÇÕES FINAIS}

Vivemos numa época de grandes mudanças e as empresas têm que encontrar uma maneira de se adequar à nova realidade do mercado, no qual agilidade, flexibilidade e inovação são consideradas características fundamentais para sobrevivência.

A adoção de novas tecnologias gera conflitos. Inovações relacionadas a computadores e automação, incorporadas a processos de produção, são relativamente recentes e ainda pouco estudadas. Todavia, hoje, toda empresa que quer estar competitiva deve investir cada vez mais em novos recursos tecnológicos.

As tecnologias da informação têm aspectos positivos e negativos. Se de um lado exigem novas práticas de trabalho, afetam interesses, valores e rotinas há muito cristalizados nos indivíduos, eliminam tarefas e geram desemprego e realimentam a automação, por outro impõem aperfeiçoamento contínuo em função das necessidades e oportunidades de negócios, segundo Marcovitch (1996).

RAI - Revista de Administração e Inovação, São Paulo, v. 1, n. 2, p. 42-54, 2004. 
Torna-se praticamente impossível sustentar o crescimento de uma empresa ou sua participação no mercado, sem os benefícios decorrentes do uso mais intenso da Tecnologia da Informação. As decisões dos empresários atualmente passam pelo crivo da estruturação do conhecimento compartilhado e não mais individualizado. $\mathrm{O}$ impacto imediato dessa mudança se deu na melhoria da qualidade das informações, uma vez que ela possibilita interface entre os profissionais dentro da empresa, além de provocar o estreitamento da relação com todos os participantes da cadeia produtiva. Em outras palavras, a tecnologia da informação ocupa, atualmente, um papel estratégico nas organizações, uma vez que, através dela ganha-se em competitividade, de acordo com Porter (1990).

Diante disso é que o planejamento adequado de tecnologia da informação deve ser uma realidade. Fundamental nesse processo, inclusive para a obtenção dos resultados esperados é a necessidade de treinamento intensivo para o trabalho com novos sistemas e novas ferramentas. Fornecedores e clientes também percebem as mudanças.

Como visto anteriormente, é extremamente importante a disponibilidade dos recursos, alicerçados numa estrutura de comunicação muito consistente.

Segundo Gates, Myhrvold e Rinearson (1995), ao longo da próxima década, as empresas do mundo inteiro transformar-se-ão. Os programas tornar-se-ão mais amigáveis e as empresas basearão os sistemas nervosos de suas organizações em redes que alcançarão não apenas todos os funcionários, mas fornecedores, consultores e clientes. Como resultado, teremos empresas mais eficazes e, com freqüência, menores.

Essa integração permite o acesso a um volume significativo de informações que propicia maior flexibilidade à empresa para negociar com seus clientes e fornecedores, aumentando a competitividade em termos globais. Mais uma vez é a globalização presente.

$\mathrm{O}$ ser humano bem treinado é o diferencial na competitividade. Ele precisa sempre aprender. Na medida em que a tecnologia (hardware e software) está disponível no mercado e qualquer empresa pode adquiri-la, inclusive uma concorrente, a vantagem competitiva será obtida pela que melhor explorar os recursos dessa tecnologia. Se todas as empresas tiverem acesso à mesma tecnologia, a diferença virá através da forma que a mesma é utilizada, e isso depende fundamentalmente do ser humano. Finalmente, verifica-se que há uma série de componentes que fazem a assimilação da moderna visão da Tecnologia da Informação algo desafiante. $\mathrm{O}$ bom entendimento desse processo é necessário para o desenvolvimento de uma estratégia eficaz voltada para o próprio gerenciamento.

Buscando dedicar os sistemas às aplicações que atendam prioritariamente os fatores críticos de sucesso da empresa, que participem no valor adicionado dos produtos/serviços e que sejam devidamente gerenciados em consonância com o impacto estratégico que tenham, podemos dizer que a tecnologia da informação numa empresa enfoca o que é importante, atende o que é necessário, racionaliza e corta redundâncias e suporta o que é crítico.

\section{REFERÊNCIAS}

AMATO NETO, J. Globalsourcing e padrões de fornecimento no complexo automobilístico brasileiro. In: ENCONTRO NACIONAL DE ENGENHARIA DE PRODUÇÃO, 16., 1996, Piracicaba. Anais. Piracicaba: UNIMEP/ABEPRO/MULTIVIEW, 1996. 1 CD-ROM.

CONTÁGIO global. O Estado de S. Paulo, São Paulo, 28 fev. 1999. p. H-1.

RAI - Revista de Administração e Inovação, São Paulo, v. 1, n. 2, p. 42-54, 2004. 
Demandas de integração de tecnologia da informação em empresa do setor de autopeças. um estudo de caso CORRÊA, H.L.; GIANESI, I.G.N.; CAON, M. Planejamento, programação e controle da produção MRP II/ERP: conceitos, uso e implantação. 2. ed. São Paulo: Atlas, 1999. 411 p.

COUTINHO, L.G.; FERRAZ, J.C. (Coord.). Estudo da competitividade da indústria brasileira. Campinas: Editora Unicamp, 1995.

DAVIS, S. O futuro perfeito. São Paulo: Nobel, 1990. 232 p.

FERRO, J.R. O Brasil na rota da mentalidade enxuta (apêndice especial: a mentalidade enxuta nas empresas). Rio de Janeiro: Campus, 1998.

GATES, B.; MYHRVOLD, N.; RINEARSON, P. A estrada do futuro. São Paulo: Companhia das Letras, 1995. $347 \mathrm{p}$.

HOFFMAN, K.; KAPLINSKY, R. Driving force: the global reestruturing of technology, labour and investment in the automobile and components industries. Boulder: Westview, 1988.

MARCOVITCH, J. (Org.). Tecnologia da informação e estratégia empresarial. São Paulo: FEA-USP, 1996. $116 \mathrm{p}$.

PORTER, M.E. Vantagem competitiva. Rio de Janeiro: Campus, 1990.

TAPSCOTT, D. Economia digital. São Paulo: Makron Books, 1997.

WOMACK, J.P.; JONES, D.T. A mentalidade enxuta nas empresas: elimine o desperdício e crie riqueza. Rio de Janeiro: Campus, 1998.

\title{
THE DEMANDS OF INTEGRATION OF INFORMATION TECHNOLOGY IN AN ENTERPRISE OF AUTOMOBILE PIECES: A CASE STUDY
}

\begin{abstract}
The present work intends to show the demands of integration of information technology in an enterprise of the automobile pieces sector. The panning performed to deal with such demands considers the aspects of communication nets, equipments, operational and applicative systems and impacts in the organization. The market globalization has brought changes in the way the world and the Brazilian automobile industry performs. As a consequence of that situation the Brazilian section of automobile pieces was also affected, needing to act to quickly fit in its relationship with its main costumers, the assembly companies. The enterprise where this case study occurs is inserted in this context. Associated to this process, it has also to attend the unification strategy in the information processing net of the group as a whole.
\end{abstract}

Keywords: Globalization; Information Technology; Automobile industry; Industry of Automobile pieces.

RAI - Revista de Administração e Inovação, São Paulo, v. 1, n. 2, p. 42-54, 2004. 
Data do recebimento do artigo: 14/10/2003

Data do aceite de publicação: 25/11/2003

RAI - Revista de Administração e Inovação, São Paulo, v. 1, n. 2, p. 42-54, 2004. 